eCommons@AKU

December 2016

\title{
Shining a light on nursing art in Pakistan
}

Shirin Rahim

Aga Khan University, shirin.rahim@aku.edu

Rafat Jan Ruknuddin

Aga Khan University, rafat.jan@aku.edu

Kathryn L. Gramling

University of Massachusetts Dartmouth, USA.

Follow this and additional works at: https://ecommons.aku.edu/pakistan_fhs_son

Part of the Nursing Midwifery Commons

\section{Recommended Citation}

Rahim, S., Ruknuddin, R. J., Gramling, K. L. (2016). Shining a light on nursing art in Pakistan. International Journal for Human Caring, 20(4), 202-205.

Available at: https://ecommons.aku.edu/pakistan_fhs_son/150 


\title{
Shining a Light on Nursing Art in Pakistan
}

\author{
Shirin Rahim, MScN, Aga Khan University; Rafat Jan Ruknuddin, PhD, Aga Khan University; Kathryn L. Gramling, PhD, \\ University of Massachusetts Dartmouth; USA; Ambreen Tharani, MScN, Aga Khan University
}

Abstract

Nursing is considered both science and art. Artful nursing has been essential for holistic nursing practice since the time of Nightingale, but it is getting neglected and has been lately limited to nursing literature (Gramling, 2004). This qualitative study seeks to gain an understanding of the perceptions of active nurses in Pakistan about nursing art and yields four major themes: artful nursing is embedded in humane responsiveness, artful nursing has healing power, artful nursing is a satisfying experience, and artful nursing is invisible in nursing practice. Study participants valued nursing art, and their perceptions illuminate Watson's Theory of Human Caring (1988).

Keywords: Art, craft, art of nursing, nursing arts, aesthetics, creativity, nursing skill

\section{Background}

The concept of the art of nursing dates back to Florence Nightingale's environmental theory and her book Notes on Nursing (1859), which explicitly addressed this concept as fine art and associated it with devotion in nursing. The art of nursing was also labeled as craft and associated with a process of transformation from illness to wellness (Collingwood, 1958; Gary, 2012). Carper (1978) called the art of nursing aesthetics and associated it with one of the ways of knowing in nursing. Furthermore, she warned that if nursing art is left behind, it may cause partial utilization of knowledge and the loss of the wholeness of nursing forever. The art of nursing has been considered as a guiding principle for nurses in understanding patients' suffering (Gaydos, 2004; Watson, 1988), creating coherence (FinfgeldConnett, 2008; Watson, 1988), working toward a skillful nursing practice (Johnson, 1994; Watson, 1988), performing with creativity to meet individual patient needs (Appleton, 1993; Watson, 1988), and creating a patient-centered, caring process facilitating healing to the highest possible level (LeVasseur, 2002; Peplau, 1988; Watson, 1988; Wright, 2006).

Literature suggests that the art of nursing is being neglected in nursing practice (Gramling, 2004), and that nurses who fail to appreciate the art of nursing are usually more task oriented and dexterous, engrossed in technical skills without exhibiting the elements of humanity, caring, and patient centeredness that are the core of the art of nursing (Chinn, 2001; Gaydos, 2004; Gramling, 2004).

\section{Aim}

This study aims to discover the perceptions of the art of nursing in the context of nurses in Pakistan, with the hope of facilitating an understanding and application of the art of nursing in their nursing care.

\section{Method \\ Design \\ A qualitative descriptive design was adopted for this study, using one-to-one interviews.}

\section{Setting}

The research was conducted in a tertiary-care university hospital in Karachi, Pakistan. Nurses meeting the inclusion criteria were recruited using a purposive sampling strategy. They were enrolled from the five in-patient units of the hospital-namely the intensive care unit, cardiac intensive care unit, and adult medical, adult surgical, and pediatric units-after written permission was obtained from the departmental head. Participants from the five units were invited for the study, but only 10 participants signed the consent form and were recruited. Data collection was done from April to May 2013 using a semistructured interview guide that was pilot tested for language, comprehension, and preliminary analysis. The interviews variably lasted 60-90 min. The interviews were audio recorded and then transcribed by researchers.

A brief demographic profile of the participants was obtained at the time of the interview. The study participants were three male and seven female nurses. Their ages ranged from 25 to 40 years, and their work experience from 2 to 8 years. The participants belonged to five different areas of practice, and their professional qualifications also varied: Six participants had a diploma, three had a bachelor's degree, and one had a master's degree in nursing.

\section{Data Analysis}

Data were manually analyzed, guided by Creswell's (2013) steps of content analysis (Table 1).

\section{Trustworthiness}

The rigor of this study was maintained using Lincoln and Guba's (1985) criteria for maintaining the trustworthiness of research. The participants were requested to review their own transcripts and verify whether the researcher had captured their true perceptions as they had intended to share. The process of constructing codes, categories, and themes was thoroughly discussed with the supervisor and committee members to obtain their consensus before these were finalized. The integrity of the findings was also ensured by verifying them with the supervisor, the committee members, and the participant themselves.

\section{Ethical Considerations}

The ethical considerations of the study were fulfilled through obtaining approval from the university ethics review committee (2459-SONERC-13), permission from the head of the tertiarycare University Hospital Karachi from where data were collected, and written consent from each participant. Principles of autonomy, anonymity, and confidentiality were maintained throughout the study.

\section{Results}

Four major themes emerged from our analysis of the interviews: 1) Artful nursing is embedded in humane responsiveness, 2) artful nursing has healing power, 3) artful nursing as a satisfying experience, and 4) artful nursing is invisible in nursing practice.

\section{Theme 1: Artful Nursing is Embedded in Humane Responsiveness}

The first theme explains the perception of the nurses about the meaning of the art of nursing, which is captured as humane responsiveness in patient care. Almost all the participants, irrespective of practice settings, perceived the art of nursing as a serving attitude and a desire to selflessly care for their patients with humaneness, beyond mechanical daily activities. As Participant 003 , a male nurse with 2 years of experience, put it: "If for someone nursing is an obligation or a mechanical activity, then it is not artful. I should serve my patients as human beings: treat them with love, affection, and with complete devotion."

Participants described three characteristics of artful nursing which enhance humane responsiveness; these are devotion, being considerate toward patients' suffering, and expression of affection through gestures.

According to Participant 010, a female nurse with 8 years of experience, "The art of nursing is the devotion of the mind, body, and soul. Whenever I come to my job, believe me, I just forget that I am a mother, I am somebody's wife, and I have a family." Participant 007, a female nurse with 4 years of experience, put it this way: "To me 'art of nursing' is to feel the patient's suffering and to give relief to the patients and bring a smile to their 


\section{Table 1}

Steps of Content Analysis

\section{Description as per Creswell (2013)}

In this step, the recorded data are converted into files called transcripts, which are then organized in the computer and large databases of text.

\section{Step 2: Reading and memoing}

In this step, the researcher tries to get a sense of the data as a whole and gets fully immersed in the data by reading the transcripts several times and memoing key ideas in the margins of the transcript.

\section{Step 3: Describing and classifying data into codes and themes}

This step involves aggregating the text with the same meaning within the transcript and assigning labels or codes. Tentatively, 20-25 codes are short-listed. Then codes covering the same meaning or idea are merged to form 10-15 categories, which are finally reduced to five or six themes.

\section{Step 4: Interpreting data}

This step involves abstracting out the larger meaning of the data, beyond the themes, and linking these meanings and interpretations to the general literature developed by others for the phenomenon under study.

\section{Step 5: Representing and visualizing the data}

This step is the final phase of data analysis, in which the researcher represents data in a tabular or figure form, using a $2 \times 2$ table, a matrix, or a hierarchical tree diagram showing levels of abstraction of data, with the most abstract information at the top of the tree.

\section{Adaptation for This Study}

Data analysis was initiated by converting the audio-recorded interviews into the verbatim transcripts and translating them into English. These transcripts and translations were given code numbers, put in a uniform format having five columns (transcription, translation, code, categories, and theme), and organized in ring binders and electronic folders.

Complete immersion in the data was ensured by reading and rereading transcripts several times, to get an in-depth understanding and description of the phenomenon.

Each paragraph of each transcript was given a code. Ideas with the same meaning within the transcript were merged under one code. Then similar codes with the same meaning were merged together to form categories. Then common themes were constructed by analyzing all the categories for connection and similarity. To support each theme, relevant quotes of participants were identified from all the transcripts and mentioned in front of each theme, along with the participant's code.

The themes were finally interpreted as data findings and verified with the supervisor and committee members for integrity and reliability. They were compared with the available literature to find similarities and differences of the ideas the study identified.

A hierarchical tree diagram of categories and themes was developed which provided a comprehensive analysis of the data for their usefulness in clinical practice. face." She also provided practical guidelines: "Nurses' gestures, the softness of voice, the way she presents herself, her body language, her facial expressions, all should be so down-to-earth to show that she cares."

\section{Theme 2: Artful Nursing has Healing Power}

The second theme of the study highlights the nurses' perceptions about the impact of the art of nursing on patients' health and well-being. Nurses identified positive outcomes of artful nursing revealed in the form of enhanced satisfaction, good compliance, and a feeling of relief, hope, and assurance that someone is there to care for them. "When we treat them as human beings and respect them," said Participant 007, "then the patients cooperate with us during the treatment, show good compliance, and follow all the instructions ..., and this ... [affects] their health in a positive way."

\section{Theme 3: Artful Nursing is a Satisfying Experience}

The third theme reveals that practicing the art of nursing is satisfying for nurses themselves. When nurses help their patients by practicing the art of nursing, they themselves feel happy and contented. According to the study participants, practicing the art of nursing makes them feel motivated and keen to go on caring for their patients with love and compassion, as Participant 010 expressed: "It is a different feeling. It satisfies you and your patients and it brings a sense of achievement and provides power for doing more good."

\section{Theme 4: Artful Nursing is Invisible in Nursing Practice}

The fourth theme highlights issues of practicing the art of nursing. These issues pertain to the working environment, lack of management support, nurses' personal deficiencies, and sociocultural differences between the nurses and their patients.
Most participants_including Participant 004, a male nurse with 2 years of experience-found workload as a major hindering factor: "Workload and double duties prevent you from giving time to patients; person gets tired and then starts ignoring patients. Nurse-patient interaction becomes only a formality to be fulfilled."

Along with this, ineffective mentorship and lack of reinforcement for the art of nursing were highlighted as challenges, as by Participant 003: "Lack of efficient mentorship hinders our practice of the art of nursing. ... We learn to work in the same way [like our seniors] and become efficient machines rather than nurses practicing the art of nursing."

A few participants shared that management was quite task oriented and nurses are appraised on the completion of the tasks and their related documentation rather than on practicing artful nursing. Participant 003 said, "We are appraised [by management] on how competently we perform skills and document them and not on how much 
time we spend with our patients listening to their concerns."

\section{Discussion}

The thematic results of this study are closely aligned with the perspective of nursing art as articulated by Jean Watson. This study has added support for the possible cross-cultural congruency of Watson's Theory of Human Caring (1988), which is grounded in a humanistic philosophical foundation and ethics. Three themes of the art of nursing that emerged from the current studyhumane responsiveness, healing power, and satisfying experience-mirror the core precepts of Watson's transpersonal caring art, defined as nurses' ability to maintain and guard patients' dignity, respect, and humanness. According to Watson, the transpersonal art is a "special kind of human care relationship, a caring occasion" where there is "high regard for the whole person and their being-in-the-world" (1985, p. 63), not only for the one being cared for but also for the one who is caring. As Watson says, "It is on the capacity of one human being to receive another human being's expression of feelings and to experience those feelings for oneself that the artistic activity of nursing and caring is based" (Watson, 1985, p. 67).

The nurse's capacity to enter into human caring art is predicated on humane responsiveness, grounded in an altruistic mindset and sensitivity to self and others. Additionally, the 10 carative factors of Watson's theoryparticularly the practice of humanistic trusting relationships, being sensitive to the feelings of others, instilling hope for transforming a person from illness to wellness, and creating a healing environment for patients-very well describe how human dignity is preserved and human indignity alleviated in the health and illness experiences when caring art is enacted. Watson also believes that nurse and patient both gain satisfaction from the art of nursing: patients in the form of healing and relief from their suffering, and nurses in the form of contentment and self-actualization. Lastly, Watson's concern for promoting human care values in nursing and health care are motivated by a "health" care system which she believes has "submerged" caring values in all its aspects, be it technical, managerial, or financial. Watson views the art of nursing, as caring, to be the moral ideal which will preserve the human in critical times.

All of these specifics of Watson's theory are very well tied to the themes revealed in the current study findings, and it may not be an exaggeration to label nursing art as a replica of Watson's Caring Science.

The study participants believe artful nursing to be embedded in humaneness, where it is significant for nurses to view their patients as humans, having unique experiences and distinctive needs. According to study participants, it is only the humanistic perspective of artful nurses which allows them to be more sensitive toward patients' suffering and generates their readiness to get devotedly involved in their care. This explanation of the art of nursing is congruent with Watson's transpersonal caring (Watson, 1988) and with a variety of studies grounded in Watsonian theory and the belief that seeing the patient as a unique human being with dignity and worth is the lens that further guides nurses' artful actions of being considerate and devoted in their care (Appleton, 1993, Chinn, 2001; Edward, 1998; Gramling, 2004; LeVasseur, 2002; Peplau, 1988).

The next description of the art of nursing that is highlighted by study participants is knowing patients' needs and trying to fulfill those needs in the best possible way. Participants strongly believed that all the nursing actions become insignificant if they are not in accordance with the patients' needs. Philosophically, this expression of knowing patient's needs matches with Carper's (1978) expression of aesthetic knowing, which allows an artful nurse to get connected with patients, enter into their worlds, gain knowledge of the patients' feelings and experience, and provide them individualized care according to the needs expressed by each patient.

The third characteristic of artful nursing which study participants affirmed is developing a sense of devotion and compassion toward patients to be able to genuinely help them in lessening their sufferings and providing them relief. This finding is similar to the published literature, explaining the idea that artful nurses are devoted and compassionate and that they constantly reassure their patients that they are there for them (Appleton, 1993; Goldsmith, 2011; Mitchell \& Cody, 2002; Nightingale, 1859; O'Brien, 2011). This devotion and compassion are related more to the "being" role of nursing, or to exhibiting expressive caring, than to the "doing" role of nursing, or exhibiting instrumental caring

(Pearcey, 2007; Woodward, 1997).

Apart from the describing the art of nursing, the study participants shared its outcome for patients and nurses. For patients, artful nursing provides hope and motivation, which encourage them to participate in self-care, take ownership of their own health, and ultimately move on the path of healing. This finding is supported by other studies in the literature explaining that artful nursing enhances the welfare of humanity in terms of promoting patients' physical, mental, spiritual, and emotional healing, providing a sense of security, and encouraging patients' participation in self-care (Finfgeld-Connet, 2008; Goldenberg, 1999; Gramling, 2004; Price et al., 2007). For nurses, artful nursing promotes inner satisfaction and motivation, leading to further utilization of artful nursing in patient care. The study participants acknowledged that engaging in the artful experience is fruitful for the nurses' own mental and emotional well-being. This discovery also has evidence in the literature, which mentions that the art of nursing has proved to be beneficial for nurses' professional growth and promotes a sense of accomplishment that serves as a reward to perpetually promote the further practice of the art of nursing (Finfgeld-Connett, 2008; Gramling, 2004). The study notably identified that Pakistani nurses seemed enthusiastic about benefiting patients and themselves by making the art of nursing a permanent and inevitable feature of their nursing practice, but they experienced several challenges in doing so.

Lastly, the study participants perceived the art of nursing to be less visible within the practice of Pakistani nurses. According to the study participants, artful nursing gets stifled due to heavy workload, routine hospital tasks, and lack of emphasis on the use of soft communication skills during nursing practice. As a result, nurses shift their priorities from artful nursing to fulfilling patients' medical and diagnostic needs, and they view artful nursing practice as an optional or nonessential aspect of the nursing practice. The literature very well supports the notion of a shift in nurses' priorities from artful to task-oriented nursing (Davison \& Williams, 2009; Pearcey, 2007). Pajnkihar (2007) quotes many nursing authors who claim that in the current medical model of nursing practice, nurses are left with too little time to understand the holistic needs of patients and to demonstrate caring gestures that build nurse-patient trust and interpersonal connectedness. Nurses shared that management is more interested in completion of tasks on time, forcing nurses to become task-oriented machines rather than compassionate care providers.

The study participants admit that they also do not attempt to look for ways to enhance artful nursing practice in terms of competence in communication, body language, self-confidence, and a self-reflective attitude pertaining to the art of nursing. The literature suggests that in working conditions where nurses do not get enough support and encouragement from management, they themselves need to be courageous enough to grow their artful skills by developing competence in communication, body language, self-confidence, and a self-reflective attitude pertaining to the art of nursing (Chinn, 2001).

All the participants were excited about reflecting on this concept and trying to practice it. Upon reflection, almost every participant-even those who said that they had not thought about this concept before-was able to describe the meaning of the art of nursing, as per their understanding and perception. The nurses' readiness to engage in dialogue about the concept of nursing art may indicate a desire to share and grow an underdeveloped aspect of 
their professional selves. However, as Roach (2002) reminds us, we need to "call forth" professional caring and it must be nurtured.

\section{Limitations of the Study}

The limitations of the study are its single setting and relatively low sample size. More research is required in the future to validate our findings. However, the data were saturated, and the findings of this study can serve as the first introductory exploration of the art of nursing in this country and lead to a larger study with many nurses at multiple sites and from multiple dimensions, such as academia and nursing administration.

\section{Implications: Practice, Education, and Research}

The professional practice environment must be enhanced so that artful nursing can be easily practiced, recognized, and rewarded. Nursing administrators should conduct discussion forums for nurses to share, and have exposure to, each other's stories about the art of nursing in practice. Aspects of artful nursing practice, such as communication, use of appropriate body language and nonverbal gestures, and demonstration of humane responsiveness, should be a part of nursing appraisals. More importantly, they should be noticeably acknowledged, on a regular basis, to motivate nurses to use the art of nursing in their practice.

Nursing education should develop creative ways to integrate the art and the science of nursing. Through academia, insights regarding the meaning, importance, and application of the art of nursing should be inculcated in student nurses so that humane responsiveness is balanced with modern technology in providing healing and in the well-being of both patients and nurses. Only by doing this can the true spirit of nursing become alive; otherwise, nursing will turn into a technically driven dehumanized practice where nurses treat diseased bodies but are not able to reach to the deep human emotions related to healing, empathy, and compassion that are the core elements of nursing practice.

Research studies should focus on practical ways to enhance nurses' communication and reflective skills to understand and practice the art of nursing, modify their care according to patients' needs, and help patients feel the humaneness and compassion within the care they receive. The study also invites future researchers to conduct impact studies to highlight the contribution of artful nursing practice toward patients' health outcomes.

\section{Conclusion}

Study findings revealed that Pakistani nurses are able to articulate the meaning of the art of nursing upon reflection, they know that nursing art promotes satisfaction in both patients and nurses, and they all struggle to make it a reality in practice. Pakistani nurses also enumerated the challenges which prevent artful nursing from being a prominent feature of their nursing practice. As the first of its kind in Pakistan, this study has contributed to the literature on multicultural perspectives of the art of nursing. It indicates that in spite of geographic, national, and cultural influences, the study participants expressed similar ideas about the art of nursing as those reflected in Western culture.

\section{References}

Appleton, C. (1993). The art of nursing: The experience of patients and nurses. Journal of Advanced Nursing, 18, 892-895.

Carper, B. (1978). Fundamental patterns of knowing in nursing. Advances in Nursing Science, 1, 13-23.

Chinn, P. L. (2001). Toward a theory of nursing art. In N. Chaska (Ed.), The nursing profession: Tomorrow and beyond (pp. 287-297). Thousand Oaks, CA: Sage.

Collingwood, R. G. (1958). The principles of art. Oxford, United Kingdom: Oxford University Press.

Creswell, J. W. (2013). Qualitative inquiry and research design choosing among the five approaches (3rd ed.). London, United Kingdom: Sage.

Davison, N., \& Williams, K. (2009, September 2228). Compassion in nursing 2: Factors that influence compassionate care in clinical practice. Nursing Times, 105(37), 18-19.

Edward, S. (1998). The art of nursing. Nursing Ethics, 5(5), 393-400.

Finfgeld-Connett, D. (2008). Concept synthesis of the art of nursing. Journal of Advanced Nursing, 62(3), 381-388.

Gary, K. (2012). Collingwood's aesthetics. The Stanford Encyclopedia of Philosophy. Retrieved from http://plato.stanford.edu/ archives/fall2012/entries/collingwoodaesthetics

Gaydos, H. L. (2004). Making special: A framework for understanding the art of holistic nursing. Journal of Holistic Nursing, 22, 152-162.

Goldenberg, G. (1999). Sarah Sheets Cook: The invisible nurse. The Academic Nurse, 16(1), 26-28.

Goldsmith, J. (2011, Sept. 20). The NMC code: Conduct, performance and ethics. Nursing Times, 107(37), 12-14.

Gramling, K. L. (2004). A narrative study of nursing art in critical care. Journal of Holistic Nursing, 22, 379-398.

Johnson, J. (1994). Dialectic analysis of concerning the rational aspect of art of nursing. Journal of Nursing Scholarship, 28, 169-175.

LeVasseur, J. (2002). A phenomenological study of the art of nursing: Experiencing the turn. Advances in Nursing Science, 24(4), 14-26.

Lincoln, Y. S., \& Guba, E. G. (1985). Naturalistic inquiry. Newbury Park, CA: Sage.

Mitchell, G., \& Cody, W. (2002). Ambiguous opportunity: Toiling for truth of nursing art and science. Nursing Science Quarterly, 15(1), 71-79.

Nightingale, F. (1859). Notes on nursing: What it is and what it is not. London, United Kingdom: Harrison.

O'Brien, M. E. (2011). Spirituality in nursing: Standing on holy ground (4th ed.). New York, NY: Kevin Sullivan.

Pajnkihar, M. (2007). Is caring a lost art in nursing? International Journal of Nursing Studies, 45, 807-809.

Pearcey, P. (2007). Tasks and routines in 21st century nursing: Student nurses' perceptions. British Journal of Nursing, 16, 296-300.

Peplau, H. (1988). The art and science of nursing: Similarities, differences, and relations. Nursing Science Quarterly, 1(1), 8-15.

Price, S., Arbuthno, E., Benoit, R., Landry, D., Landry, M., \& Butler, L. (2007). The art of nursing: Communication and self-expression. Nursing Science Quarterly, 20(2), 155-160.

Roach, M. S. (2013). Caring: The human mode of being. In Caring in Nursing Classics: An essential Resource, (pp. 165-179). New York: Springer Publishing Company

Watson, J. (1985). Nursing: The philosophy and science of caring. Boulder, CO: University of Colorado Press.

Watson, J. (1988). Nursing: Human science and human cure. New York, NY: National League for Nursing.

Woodward, V. M. (1997). Professional caring: A contradiction in terms? Journal of Advanced Nursing, 26, 999-1004.

Wright, S. (2006). Finest of the fine arts. Nursing Standard, 21(4), 20-22.

Author Note
Shirin Rahim Instructor Aga Khan University
School of Nursing and Midwifery (AKUSONAM)
Dr. Rafat Jan Professor AKUSONAM
Dr. Kathryn L. Gramling Associate Professor,
University of Massachusetts Dartmouth; USA
Ambreen Tharani Assisstant Professor
AKUSONAM
Correspondence concerning this article should
be addressed to Shirin Rahim, House \# A526
Block C North Nazimzbad Karachi Pakistan.
email Address: shirin.rahim@aku.edu Alternative
email: rajan.shirin@gmail.com

2016, Vol. 20, No. 4 